\title{
Implementasi Konsep "BETAH" dalam Pelaksanaan Ujian Akademik Penerimaan Polri Terpadu Polda Sumatera Utara berbasis Komputer dan Manual
}

\author{
${ }^{1)}$ Tonni Limbong \\ UNIKA Santo Thomas Medan, JI. Setiabudi No. 479 F, Sumatera Utara, Indonesia \\ http://www.ust.ac.id, Email :tonni.budidarma@gmail.com \\ 2)I.K. Suardana \\ Biro Sumber Daya Manusia (SDM) Kepolisian Daerah Sumatera Utara \\ Jl. Tanjung Morawa Km. 10.5, Timbang Deli, Medan, Sumatera Utara
}

\begin{abstract}
The current examination must be clean and honest in order to get good and integrity resources so that the institutions that carry out the reception of human resources will be satisfied and successful. Likewise in the current era of computerization the North Sumatra regional police in carrying out personnel recruitment applies the concept of "TRUE" which means "Clean Transparent Accountable and Humanistic" with the jargon of Clear and Clean. Examination of the Academic Exams in accordance with the instructions and instructions from the National Police Headquarters of the Republic of Indonesia is carried out by combining computer technology with conventional models / manuals with Computer Answer Sheets (LJK). All selection participants who passed and did not pass were satisfied because with this method each participant could see the selection process from beginning to end in a very transparent manner, so that the perception of the community had always been negative thinking that the national police selection was not free from KKN practices. The concept of CONCRETE is a very good method and can be accounted for by all the elements involved in the process and can realize the selection process that is "Clear and Clean".
\end{abstract}

Kata Kunci : Sibetah, Clear and Clean, Penerimaan Polri, Ujian Akademik

\section{PENDAHULUAN}

Proses pelaksanaan rekrutmen anggota polri (Tantama, Bintara, SIPSS dan Taruna Akpol) T.A. 2018 harus dilakukan secara objektif dan jujur. Seluruh proses harus clear and clean jangan ada penyimpangan seperti yang selama ini menjadi rumor di masyarakat (Arief Effect, 2018 : 61). Rekrutmen yang bersih merupakan perintah Kapolri Tito Karnavian dan juga arahan Presiden Jokowi saat melantik Kapolri [1], yang diharapkan slogan dan jargon yang ada pada rompi panitia juga bertujuan untuk sosialisasi kepada masyarakat [4].

Rekrutmen merupakan proses mencari, menemukan, dan menarik para pelamar untuk dipekerjakan dalam dan oleh perusahaan. Rekrutmen dapat dikatakan sebagai proses untuk mendapatkan sejumlah SDM (karyawan) yang berkualitas untuk menduduki suatu jabatan/pekerjaan dalam suatu perusahaan. Proses rekrutmen berlangsung mulai dari saat mencari pelamar hingga pengajuan lamaran oleh pelamar [2].

Seleksi adalah kegiatan dalam manajemen SDM yang dilakukan setelah proses rekrutmen selesai dilaksanakan, yang berarti telah terkumpul sejumlah pelamar yang memenuhi syarat untuk kemudian dipilih mana yang dapat ditetapkan sebagai pegawai / karyawan dalam suatu lembaga/ instansi /perusahaan. Adapun jenis-jenis seleksi adalah : Seleksi Administrasi, Seleksi secara tertulis, dan Seleksi tidak tertulis. Ujian akademik atau sering juga disebut dengan Tes Potensi Akadmik adalah sebuah tes untuk mengukur sejauh mana kemampuan pelamar berupa kemampuan verbal, keterampilan kualitatif, serta kecerdasan persepsi. Tes Potensi akademik biasanya digunakan sebagai syarat tes seleksi dalam penerimaan mahasiswa maupun dalam penerimaan pegawai [5], karyawan atau sumber daya manusia (SDM) di sebuah perusahaan yang membuka lowongan kerja sering juga disebut dengan ability test[3].

Penerimaan terpadu anggota polri saat ini sudah sangat transparansi dengan langkahlangkah yang diambil saat ini yakni dengan melibatkan pihak eksternal sebagai pengawas. Adapun pihak eksternal yang terlibat adalah dari pihak praktisi dan juga akademisi. Proses seleksi seperti ini masih hanya ada dijumpai di lembaga kepolisian negara republik Indonesia sesuai dengan perintah Kapolri dengan konsep 
BETAH. Langkah ini diambil untuk mendukung proses yang transparansi dengan melibatkan pihak eksternal sebagai perwakilan dari masyarakat.

\section{METODE PELAKSANAAN}

Adapun metode pelaksanaan Ujian Akademik pada penerimaan Akpol, Bintara dan Tamtama Polri di Kepolisian Daerah Sumatera Utara T.A. 2018 harus dilaksanakan dengan konsep one day service (nilai hasil ujian harus dimunculkan hari itu juga) baik secara langsung ataupun melalui Aplikasi Sibetah Polda Sumatera Utara, ini dapat dilihat dalam gambar 1. berikut ini :

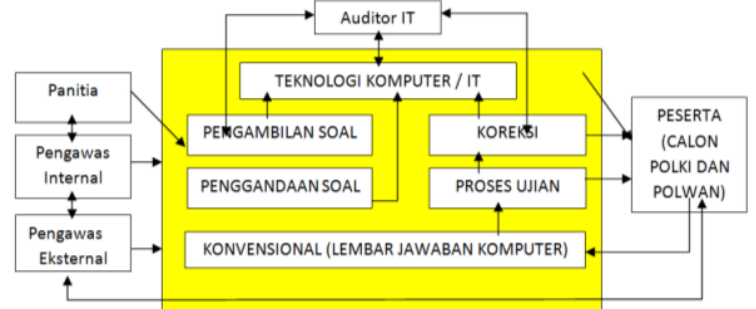

Gambar 1. Alur diagram Komponen dan

Pekerjaan dalam Pelaksanaan Ujian Akademik

Adapun kepanitiaan yang terlibat dalam mewujudkan BETAH adalah:

a. Panitia (sebagai pelaksana semua kegiatan yang berhubungan dengan Seleksi Penerimaan Anggota POLRI di Kepolisian Daerah Sumatera Utara)

b. Pengawas Internal (sebagai pelaksana yang bertanggungjawab untuk memastikan kegiatan Seleksi Penerimaan Anggota POLRI di Kepolisian Daerah Sumatera Utara) berjalan dengan baik dan benar) terdiri dari Pihak Internal POLRI yaitu Irwasda dan Propam Paminal.

c. Pengawas Eskternal (sebagai pelaksana yang bertanggungjawab untuk memastikan kegiatan Seleksi Penerimaan Anggota POLRI di Kepolisian Daerah Sumatera Utara) berjalan dengan baik dan benar) terdiri dari Pihak Eksternal POLRI yaitu HIMPSI, IDI, dan LSM Polri Watch Sumatera Utara.

d. Auditor IT (sebagai pelaksana yang bertugas untuk memeriksa dan memastikan semua peralatan yang dipakai dalam kegiatan seleksi yang berhubungan dengan IT seperti Komputer/Laptop, Printer, Scanner dan Aplikasi serta mesin Fotocopy benar bersih dan layak untuk digunakan) serta bertindak mengawas proses scanner dan pengolahan data digital sampai keluar hasil dalam hal ini yang ditunjuk adalah Fakultas IImu Komputer Universitas Katolik Santo Thomas Medan.

e. Peserta (calon siswa yang mengikuti tahapan ujian akademik, pada kegiatan
Seleksi Penerimaan Anggota POLRI di Kepolisian Daerah Sumatera Utara terdiri Calon siswa Akpol, Bintara dan Tamtama).

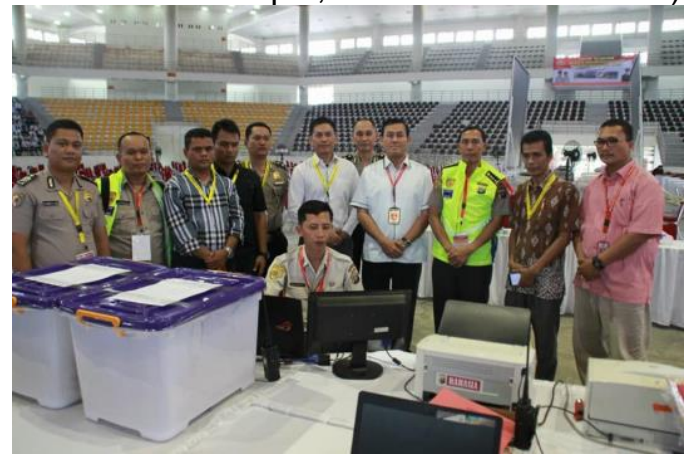

Gambar 2. Panitia dan Pengawas Pelaksanaan Ujian Akademik

\section{HASIL DAN PEMBAHASAN}

Untuk pelaksanaan kegiatan Seleksi Penerimaan terpadu Anggota POLRI di Kepolisian Daerah Sumatera Utara T.A. 2018 berjalan dengan baik dan benar yakni pada pelaksanaan ujian akademik dengan memadukan penggunaan teknologi komputer dan manual, dimana proses pengambilan soal, penggandaan soal, pemeriksaan hasil ujian menggunakan komputer dan pelaksanaan ujian dilakukan dengan manual yaitu dengan menggunakan lembar jawaban komputer (LJK).

\subsection{Persiapan}

Pada tahapan ini semua calon siswa yang sudah terdaftar dan yang dinyatakan Memenuhi Syarat (MS) setelah mengikuti Ujian Jasmani. Persiapan untuk penggandaan soal sudah disiapkan mesin foto copy dan operatornya dari pihak eksternal sesuai dengan jumlah kebutuhan. Panitia membuat ulang nomor ujian yang baru juga dengan cara mengacak tempat duduk tidak sama dengan nomor pendaftaran. Pantia menyiapkan mesin scanner dan laptop yang akan dipergunakan saat mencetak soal ujian dan mengoreksi hasil ujian (LJK) dan semua peralatan ini termasuk mesin fotocopy terlebih dahulu di audit oleh Auditor IT sebelum dipergunakan. Panitia menyiapkan Lembar Jawaban Komputer (LJK) yang sesuai dengan format mata ujian akademik yang dibagi dalam 3 bagian yaitu : Bahasa Indonesia, Matematika dan Pengetahuan Umum untuk calon Siswa Taruna sedangkan Bahasa Indonesia, Bahasa Inggris dan Pengetahuan Umum untuk calon Siswa Bintara dan Tamtama yang semua soal ini sudah disiapkan oleh Markas Besar (Mabes) Polri dalam 3 (tiga) tipe soal yang didistribusikan menggunakan aplikasi berbasis web menggunakan user dan password dari panitia, dengan format tampilan sebagai berikut : 


\begin{tabular}{|l|c|c|c|}
\hline \multicolumn{4}{|c|}{ SOAL UJIAN } \\
\hline Mata Ujian & Type Soal A & Type Soal B & Type Soal C \\
\hline Bahasa Indonesia & DITUTUP & DITUTUP & DITUTUP \\
\hline Bahasa Inggris & DITUTUP & DITUTUP & DITUTUP \\
\hline Pengetahuan Umum & DITUTUP & DITUTUP & DITUTUP \\
\hline \multicolumn{4}{|c|}{ KUNCI JAWABAN } \\
\begin{tabular}{|l|c|c|c|}
\hline Mata Ujian & Type Soal A & Type Soal B & Type Soal C \\
\hline Bahasa Indonesia & DITUTUP & DITUTUP & DITUTUP \\
\hline Bahasa Inggris & DITUTUP & DITUTUP & DITUTUP \\
\hline Pengetahuan Umum & DITUTUP & DITUTUP & DITUTUP \\
\hline
\end{tabular}
\end{tabular}

Gambar 3. Tampilan aplikasi distribusi soal dari mabes Polri berbasis web

\subsection{Pelaksanaan}

Pada hari pelaksanaan ujian, semua peserta wajib hadir sesuai dengan jadwal yang ditentukan untuk registrasi ulang (absensi kehadiran) peserta ujian harus hadir di lokasi ujian paling lama 15 menit sebelum pelaksanaan ujian, jika peserta terlambat hadir, maka dinyatakan gugur dan tidak boleh mengikuti seleksi lagi [6]. Setelah itu panitia memilih perwakilan dari peserta minimal 2 (dua) orang dan maksimal 3 (tiga) orang untuk mengundi dan memilih type soal yang akan diujikan apakah Type A, Type B atau Type C. Setelah perwakilan peserta selesai memilih soal, maka panitia menelepon mabes polri untuk mengaktifkan link download soal ujian sesuai dengan yang dipilih perwakilan peserta, kemudian panitia dari mabes membuka link pada sistem di aplikasi tersebut, selanjutnya soal di download oleh panitia daerah. Adapun tampilan dari aplikasi soal ujian berbasis web yang sudah dibuka sesuai dengan type soal yang dipilih oleh perwakilan peserta seperti berikut ini :

\begin{tabular}{|l|c|c|c|}
\hline \multicolumn{5}{|c|}{ SOAL UJIAN } \\
\hline Mata Ujian & Type Soal A & Type Soal B & Type Soal C \\
\hline Bahasa Indonesia & DITUTUP & DIBUKA & DITUTUP \\
\hline Bahasa Inggris & DITUTUP & DITUTUP & DITUTUP \\
\hline Pengetahuan Umum & DITUTUP & DITUTUP & DITUTUP \\
\hline \multicolumn{4}{|c|}{ KUNCI JAWABAN } \\
\begin{tabular}{|l|c|c|c|}
\hline Mata Ujian & Type Soal A & Type Soal B & Type Soal C \\
\hline Bahasa Indonesia & DITUTUP & DITUTUP & DITUTUP \\
\hline Bahasa Inggris & DITUTUP & DITUTUP & DITUTUP \\
\hline Pengetahuan Umum & DITUTUP & DITUTUP & DITUTUP \\
\hline
\end{tabular}
\end{tabular}

Gambar 4. Tampilan aplikasi distribusi soal yang sudah dibuka dari mabes Polri berbasis web

Pada gambar di atas, yang dibuka adalah Soal Bahasa Indonesia type B yang dipilih oleh perwakilan peserta ujian, sementara untuk kunci jawaban masih belum dibuka.

Soal yang didownload dari aplikasi dalam bentuk file kompresi (rar) dan dipassword dengan menggunakan kombinasi angka dan abjad huruf besar dan huruf kecil, lalu langkah berikutnya perwakilan peserta tadi menelepon kembali panitia pusat untuk meminta password soal tersebut dan setelah password diberikan, soal diekstrak dan dibuka melalui panitia daerah. Sebelum password diberikan oleh panitia pusat maka oleh panitia daerah diberikan kesempatan untuk memasukkan sembarang password untuk membuka soal tersebut kepada peserta ujian sampai peserta tersebut menyerah untuk menjamin keamanan soal tersebut. Kemudian perwakilan peserta ujian tadi memasukkan password yang sudah diberikan dari mabes polri untuk membuka soal ujian dan perwakilan peserta tetap berada di lokasi untuk ikut menyaksikan pembukaan soal sampai pencetakan master soal ujian yang juga dibuka secara transparansi ditampilkan menggunakan layar monitor dan LCD Projektor, yang didampingi oleh Auditor IT, pengawas eksternal, pengawas internal Irwasda dan Paminal. Setelah master soal dicetak, kemudian oleh panitia, pengawas eksternal dan pengawas internal serta auditor IT memparaf soal ujian tersebut untuk memastikan jumlah lembar soal dan jumlah halaman serta semua nomor soal tersebut lengkap.

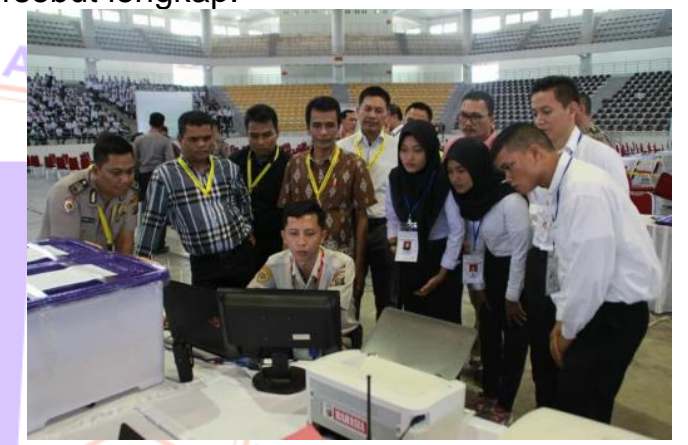

Gambar 5. Pencetakan Soal Ujian Akademik dihadapan Panitia, Pengawas dan perwakilan Peserta

Setelah itu dihadapan peserta ketua panitia ujian akademik menyerahkan soal kepihak pengawas untuk diteruskan ke petugas/operator fotocopy untuk digandakan sebanyak jumlah peserta. Setelah soal ujian digandakan kemudian dibagi kepada peserta ujian untuk dijawab pada lembar Jawaban Komputer (LJK). Pada saat penggandaan soal maka panitia membagikan LJK kepada peserta ujian dan memandu serta memberikan arahan tentang pengisian LJK agar tidak salah dan sesuai dengan format menggunakan Pensil 2B agar hasil LJK nya saat discanner dapat dibaca dengan optimal.

\subsection{Pelaksanaan Ujian}

Waktu untuk pelaksanaan ujian masing-masing mata ujian diberikan waktu 90 (Sembilan puluh) menit untuk soal sebanyak 50 soal ujian. Di layar projector dibuat jam stopwatch menggunakan aplikasi komputer dengan hitungan mundur agar peserta ujian dan panitia 
tahu waktu pelaksanaan ujian selesai atau tinggal berapa menit lagi.

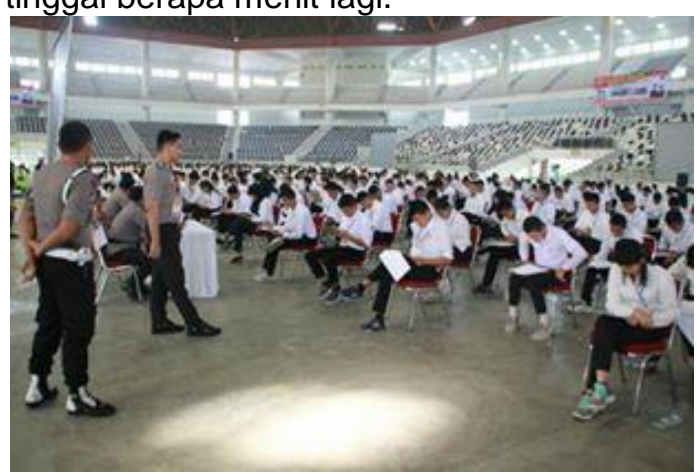

Gambar 6. Proses Pelaksanaan Ujian Akademik menggunakan LJK

Setelah pelaksanaan ujian selesai dengan ditandai jam di layar projector sudah 00.00 dan berhenti maka oleh panitia semua lembar jawaban komputer (LJK) peserta ujian dikumpulkan kemudian dihitung ulang apakah sesuai dengan jumlah peserta dan berikutnya dilakukan proses scanner LJK dihadapan semua peserta, panitia, pengawas dan khususnya Auditor IT untuk memastikan data LJK hasil scanner bersih, tidak ada kecurangan dan semua LJK hasil scanner disimpan di folder yang sudah disiapkan oleh Auditor IT.

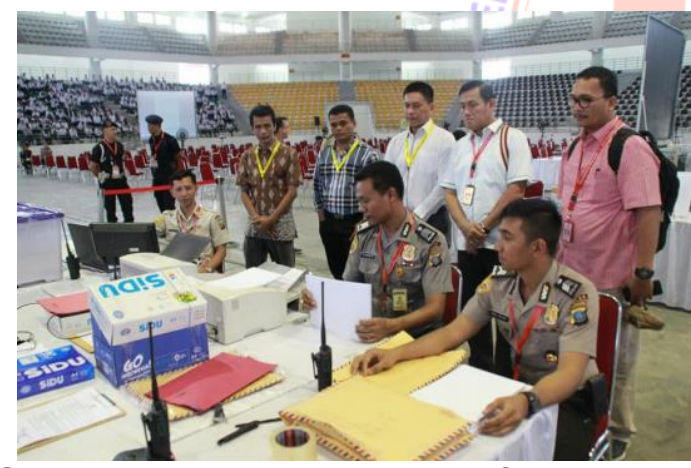

Gambar 7. Proses Pelaksanaan Scanning LJK dihadapan Pengawas Internal dan Eksternal juga Paminal Mabes Polri

\subsection{Koreksi LJK}

Setelah proses scanner Lembar Jawaban Komputer (LJK) selesai, maka berikutnya adalah tahapan untuk koreksi dimana pada saat mengoreksi, semua LJK hasil scanner tadi di ekstraksi menggunakan aplikasi OMR untuk merubah gambar (image) kedalam bentuk abjad, setelah semua LJK selesai diekstraksi kemudian dilakukan proses validasi untuk mencek apakah semua lembar jawaban komputer dapat dibaca dengan baik oleh OMR, khususnya validasi untuk nomor peserta, nama peserta harus disesuaikan dengan data induk peserta ujian.

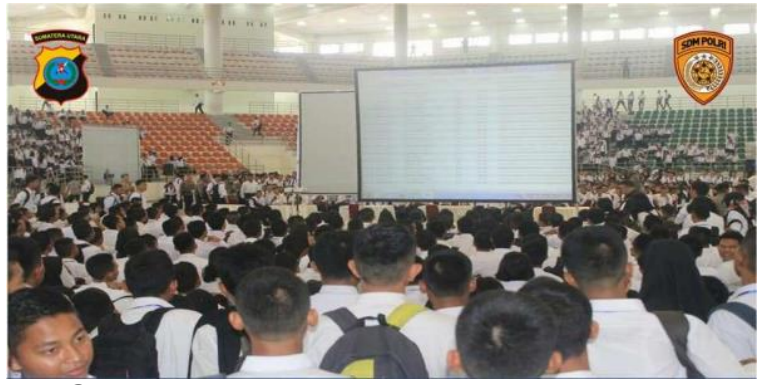

Gambar 8. Proses validasi ekstraksi LJK dihadapan semua Peserta ujian Akademik

Setelah semua selesai, kemudian data itu di ekstrak ke file excel (xls) dan disimpan di folder yang telah disiapkan dengan nama hasil_baca_LJK.xls, kemudian data ini dikirimkan ke mabes Polri melalui email yang sudah ditentukan dari mabes polri, karena ini merupakan syarat untuk meminta kunci jawaban dari setiap mata ujian. Setelah proses pengiriman selesai kemudian panitia memilih kembali perwakilan peserta ujian untuk meminta kunci jawaban ke mabes polri atau password dari kunci jawaban, yang dikirimkan melalui aplikasi untuk kunci jawabannya sedangkan password untuk membuka kunci jawabannya melalui telepon seperti pada saat meminta password soal ujian sama dengan langkah untuk pengambilan soal sebelumnya, adapun bentuk aplikasi web distribusi soal dan kunci jawaban dapat dilihat pada gambar berikut ini :

\begin{tabular}{|l|c|c|c|}
\hline \multicolumn{4}{|c|}{ SOAL UJIAN } \\
\hline Mata Ujian & Type Soal A & Type Soal B & Type Soal C \\
\hline Bahasa Indonesia & DITUTUP & DIBUKA & DITUTUP \\
\hline Bahasa Inggris & DITUTUP & DITUTUP & DITUTUP \\
\hline Pengetahuan Umum & DITUTUP & DITUTUP & DITUTUP \\
\hline \multicolumn{4}{|c|}{ KUNCI JAWABAN } \\
\begin{tabular}{|l|c|c|c|}
\hline Mata Ujian & Type Soal A & Type Soal B & Type Soal C \\
\hline Bahasa Indonesia & DITUTUP & DITUTUP & DITUTUP \\
\hline Bahasa Inggris & DITUTUP & DITUTUP & DITUTUP \\
\hline Pengetahuan Umum & DITUTUP & DITUTUP & DITUTUP \\
\hline
\end{tabular}
\end{tabular}

Gambar 9. Tampilan aplikasi distribusi kunci jawaban yang belum dibuka dari mabes Polri berbasis web

\begin{tabular}{|l|c|c|c|}
\hline \multicolumn{5}{|c|}{ SOAL UJIAN } \\
\hline Mata Ujian & Type Soal A & Type Soal B & Type Soal C \\
\hline Bahasa Indonesia & DITUTUP & DIBUKA & DITUTUP \\
\hline Bahasa Inggris & DITUTUP & DITUTUP & DITUTUP \\
\hline Pengetahuan Umum & DITUTUP & DITUTUP & DITUTUP \\
\hline \multicolumn{4}{|c}{ KUNCI JAWABAN } \\
\begin{tabular}{|l|c|c|c|}
\hline Mata Ujian & Type Soal A & Type Soal B & Type Soal C \\
\hline Bahasa Indonesia & DITUTUP & DIBUKA & DITUTUP \\
\hline Bahasa Inggris & DITUTUP & DITUTUP & DITUTUP \\
\hline Pengetahuan Umum & DITUTUP & DITUTUP & DITUTUP \\
\hline
\end{tabular}
\end{tabular}

Gambar 10. Tampilan aplikasi distribusi kunci jawaban yang sudah dibuka dari mabes Polri berbasis web

Setelah link kunci jawaban aktif, maka panitia dihadapan peserta, pengawas dan auditor mendownload kunci jawaban tersebut. 
File kunci jawaban sama seperti file soal yaitu dalam bentuk file kompresi yang dipassword. Selanjutnya melalui telepon sama seperti proses meminta password untuk soal ujian demikian juga yang dilakukan dengan kunci jawaban, perwakilan peserta meminta password dari panitia yang dari mabes polri dimana password terdiri dan kombinasi angka dan abjad. Kemudian password tersebut dimasukkan ke file kompres kunci jawaban tersebut. Setelah terbuka dengan menggunakan aplikasi koreksi ujian berbentuk excel sehingga memudahkan pengawas, auditor IT dan peserta dapat melihat keakuratan data hasil ujian dan pemasukan kunci jawaban. Setelah kunci jawaban dimasukkan maka secara otomatis nilai dari setiap peserta sudah bisa dilihat. Proses ini semua dilakukan transparansi dengan tetap memunculkan di LCD projector mulai dari awal koreksi sampai dengan selesai sehingga peserta semua dapat melihat setiap proses yang terjadi. Setelah itu hasil ujian yang sudah ada nilai dicetak dan dibagikan ke setiap peserta untuk ditandatangani memastikan apakah nilai tersebut adalah milik masing-masing peserta. Sambil proses penandatanganan, di layar LCD Projektor juga dibuat pengumuman dengan file berjalan (run scroll) agar nilai dapat dilihat oleh setiap peserta. Selain itu semua hasil seleksi juga dapat diakses di Aplikasi SIBETAH Polda Sumatera Utara oleh peserta dan orang tua.

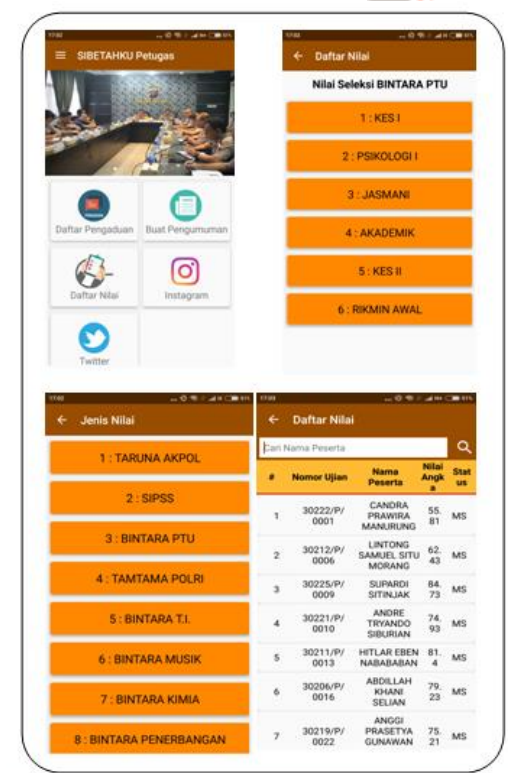

Gambar 11. Aplikasi Online Sibetah Poldasu sebagai media online pengumuman hasil ujian

\subsection{Pemusnahan Dan Audit}

Setelah pelaksanaan ujian, soal ujian akan dikumpul dan dihitung kembali harus sama dengan jumlah soal yang dibagikan pada awal ujian yaitu sebanyak peserta yang hadir. Setelah itu melalui panitia dan disaksikan oleh pengawas internal dan eksternal semua soal tersebut dibakar/musnahkan.

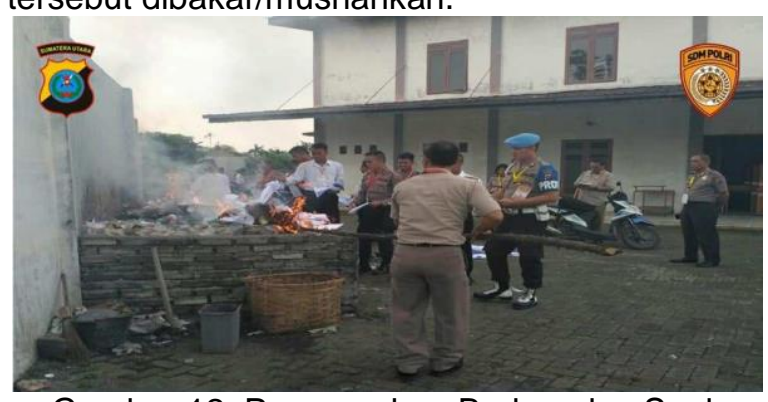

Gambar 12. Pemusnahan Berkas dan Soal

Ujian dihadapan pengawas dan peserta ujian

Setelah itu semua laptop dan mesin fotocopy juga diperiksa dan di audit oleh Auditor IT (dari pihak eksternal) bersama dengan internal yaitu Paminal dari Mabes Polri. Semua komputer / laptop yang dipergunakan saat proses seleksi diekstraksi menggunakan software basic forensic oleh pihak paminal mabes polri dan secara manual dipastikan tidak akan ada tertinggal soal lagi baik itu manual, atau digital di komputer/laptop dan juga di mesin fotocopy. Semua memory dari peralatan IT yang dipergunakan harus direset ulang dikembalikan menjadi kosong.

\section{KESIMPULAN}

Pelaksanaan ujian akademik seleksi penerimaan terpadu anggota polri T.A 2018 dengan menggunakan Teknologi IT dan model konvensional dan sesuai slogan "Bersih, Transparan, Akuntabel dan Humanis" atau BETAH mulai dari awal seleksi sampai dengan selesai, maka dapat disimpulkan:

1. Soal ujian tidak akan pernah bocor / diketahui oleh pihak pelaksana (Panitia dan Pengawas) karena soal dibuat oleh pihak mabes polri dan soal ujian dibuat dalam bentuk 3 type ( $A, B$ dan $C$ ) sehingga sangat sulit memastikan soal yang mana yang akan diujikan.

2. Hasil ujian tidak bisa dilakukan manipulasi karena sebelum meminta password kunci jawaban panitia wajib terlebih dulu mengirimkan hasil scanner LJK peserta ujian tadi ke mabes Polri, di mabes polri hasil ujian yang dikirimkan tadi juga akan di uji dengan kunci jawaban tersebut, sehingga hasil koreksi dan nilai yang ada di mabes polri tidak akan pernah berbeda dengan hasil koreksi dan nilai yang ada di panitia daerah.

3. BETAH akan berpihak pada semua elemen masyarakat yang mampu dan berkualitas maka dengan model pelaksanaan ini akan didapatkan sumber daya manusia yang 
Profesional dan sesuai dengan harapan Kapolri, dan model BETAH adalah sebuah model untuk menjunjung integritas POLRI di mata masyarakat, dengan salah satu jargon "Kami Saja Panitia Tidak Bisa Menjamin Anda Lulus, Apalagi Bukan Panitia".

4. Sistem rekrutmen Anggota Polri Terpadu T.A. 2018 yang dirancang oleh Mabes Polri sangat efektif untuk mewujudkan rekrutmen BETAH, Clear \& Clean.

\section{UCAPAN TERIMAKASIH}

1. Bapak Irjen. Pol. Drs. Paulus Waterpauw selaku Kepala Kepolisian Daerah Sumatera Utara

2. Bapak AKBP Bony Johannes Sanganadi Sirait, SIK sebagai Kabagbinkar Ro SDM Poldasu selaku Panitia Ujian akademik

\section{DAFTAR PUSTAKA}

[1]. Farouck Arnaz, ARIEF EFFECT- Setahun Revolusi Senyap di Dapur Polri, Penerbit Diandra Kreatif, Yogyakarta, 2018.

[2]. http://stiebanten.blogspot.com/2011/05/pen gertian-rekrutmen-dan-seleksi.html

[3]. https://www.temukanpengertian.com/2016/ 01/pengertian-tes-potensi-akademik.html

[4]. Lagu "Sayang" Via Vallen Versi SDM Mabes Polri dan lagu Seleksi Kece tanpa Katebelece versi Polda Sumut, 2018.

[5]. Tonni Limbong, Insan Taufik, Aplikasi Pengacak Soal Ujian Untuk Type Soal Berbasis Microsoft Word Menggunakan Metode Linear Congruent Method (LCM), Media Informasi Analisa dan Sistem, 2017.

[6]. Tonni Limbong, Efendi Napitupulu, Pardomuan Manullang, Dikte Test Applications (IMLA) Using Computer Assisted Instruction (CAI) Model, International Journal of Engineering Research and Technology: IJERT, vol. 6 Issue. 10, p 384-388, ESRSA Publication, Pvt, Ltd, 2017. 